\title{
Efficient and Stereoselective Dimerization of Pyrroloindolizine Derivatives Inspired by a Hypothesis for the Biosynthesis of Complex Myrmicarin Alkaloids
}

\author{
Mohammad Movassaghi ${ }^{*}$, Alison E. Ondrus, and Bin Chen \\ Department of Chemistry, Massachusetts Institute of Technology, Cambridge, Massachusetts \\ 02139
}

\begin{abstract}
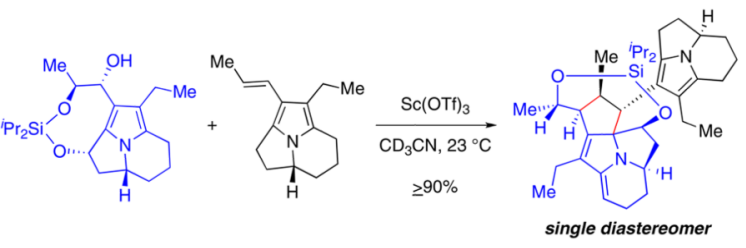

Pyrroloindolizine derivatives participate in efficient and stereoselective homo- and heterodimerization reactions upon treatment with Brønsted or Lewis acids. The distinctive ability of pyrroloindolizines to act as azafulvenium ion precursors provides direct access to both heptacyclic and hexacyclic dimeric products. The inherent reactivity of these structures suggests a concise synthesis of complex myrmicarin alkaloids via dimerization of pyrroloindolizines, and may have implications for the biosynthesis of these intriguing alkaloids.
\end{abstract}

\section{Introduction}

The complex myrmicarins are a family of structurally fascinating and air sensitive alkaloids isolated from the poison gland of the African ant species Myrmicaria opaciventris (Figure 1). ${ }^{i}$ Detailed spectroscopic studies have been used to assign the relative stereochemistries of the complex myrmicarins $430 \mathrm{~A}(4)^{\text {ic }}$ and $663(5) .{ }^{\text {id }}$ While myrmicarin $663(5)$ was isolated and fully characterized, the extreme sensitivity of myrmicarin 430A (4) required its structural assignment as a crude isolation mixture using phase sensitive 2D NMR techniques. Likewise, the fragility and limited quantities of isolated myrmicarin 645 (6) precluded its relative stereochemical assignment. An isomeric myrmicarin 430B was also identified, ${ }^{\text {ic }}$ but no structural information on this compound has been reported.

The compelling architectures of these toxic alkaloids and the challenges associated with their sensitivity inspired us to initiate a program directed at their study and total synthesis. ${ }^{\text {ii }}$ Our synthetic approach is based on our proposal that these complex molecules could be accessed from activated pyrroloindolizine derivatives (Scheme 1) through a potentially biomimetic dimerization event. ${ }^{\text {iia }}$ We have considered three possible pathways for the dimerization of myrmicarin 215 (2) to provide the heptacyclic structure of myrmicarin 430A (4). In the first scenario, we envisioned that protonation of (+)-myrmicarin 215B (2) at C9

movassag@mit.edu.

Supporting Information Available: Experimental procedures and spectroscopic data for selected new compounds. This material is available free of charge via the Internet at http://pubs.acs.org. 
could initiate a sequence of bond forming events mediated by highly electrophilic azafulvenium ion intermediates (i.e. 8, Scheme 1A). ${ }^{\text {iia }}$ In this sequence, cyclopentannulation would occur through intermolecular trapping of the tricyclic azafulvenium ion $\mathbf{8}$ by (+)myrmicarin 215B (2), followed by an intramolecular Friedel-Crafts trapping at C8b of intermediate 9 (Scheme 1A). Alternatively, the five contiguous stereocenters in myrmicarin 430A (4) may be generated in a concerted cycloaddition process involving neutral (+)myrmicarin 215B (2) and the tricyclic azafulvenium ion $\mathbf{8}$ (Scheme 1B). The reactive intermediate $\mathbf{8}$ can be generated either by $\mathrm{C} 9$-protonation of $\mathbf{2}$ or by expulsion of a leaving group at $\mathrm{C} 8$ of pyrroloindolizine derivative 7 . Consistent with FMO analysis, a $\left[6 \pi_{\mathrm{a}}+2 \pi_{\mathrm{s}}\right]$ cycloaddition ${ }^{\mathrm{iii}}$ would afford the observed stereochemistry at each of the stereocenters of myrmicarin 430A (4). Another possible dimerization manifold involves activation of (+)myrmicarin 215B (2) or a tricyclic derivative 7 as the stabilized radical intermediate 12, which could undergo intermolecular radical addition to another (+)-myrmicarin 215B (2) to give $\mathbf{1 3}$ (Scheme 1C). Subsequent 5-exo-trig radical cyclization of $\mathbf{1 3}$ (C1-C8b bond formation) would provide the heptacycle 14, which would lead to formation of myrmicarin $430 \mathrm{~A}$ (4) via oxidation and tautomerization reactions. Herein we report our studies on the reactivity of functional pyrroloindolizines pertinent to our hypothesis regarding the biosynthesis of these alkaloids. Additionally, relying on the unique reactivity of pyrroloindolizines, we discuss the development of a convergent strategy for the assembly of functional intermediates for the synthesis of complex myrmicarins.

While our initial biosynthetic hypotheses (Scheme 1A) suggested a succinct means of generating these complex alkaloids, the proposed cyclopentannulation reactions required an unprecedented mode of reactivity for vinyl pyrroles. ${ }^{\text {iv }}$ Earlier we reported the direct and highly diastereoselective homodimerization of (+)-myrmicarin 215B (2) leading to generation of a single heptacyclic product and introduction of four contiguous stereocenters. ${ }^{\text {iia }}$ In situ ${ }^{1} \mathrm{H}$ NMR monitoring revealed that Brønsted acid (trifluoracetic acid, TFA) treatment of (+)-myrmicarin 215B (2) in benzene- $d_{6}(0.050 \mathrm{M})$ resulted in complete conversion to a single new dimeric compound, namely the heptacyclic iminium ion $\mathbf{1 6}$ (Scheme 2). Deprotonation of $\mathbf{1 6}$ gave the air sensitive isomyrmicarin 430A (17). Although the direct dimerization product $\mathbf{1 6}$ was unstable to isolation, chemical modification of this compound provided stable derivatives that were amenable to full structural characterization, enabling rigorous assignment of their connectivity and stereochemistry through a combination of high field 2D NMR techniques (Scheme 2). ${ }^{\text {iia }}$ Our analysis revealed that the obtained dimer was regioisomeric at one bond and epimeric at one stereocenter to myrmicarin 430A (4). Significantly, this structure validated our mechanistic hypothesis that acid promoted activation of (+)-myrmicarin 215B (2) can provide C8 electrophilic derivatives susceptible to a highly diastereoselective attack by the vinyl group of a second equivalent of (+)-myrmicarin 215B (2).

According to this stepwise mechanism, the regiochemical difference between the myrmicarin 430A (4) and isomyrmicarin 430A (17) structures arises from the proposed Friedel-Crafts trapping of the hexacyclic iminium ion 19 (Scheme 3), where the observed heptacycle 20 possesses a C1-C3b bond (Path B) instead of the C1-C8b bond (Path A) found in the framework of the natural alkaloid myrmicarin 430A (4). Additionally, the isomyrmicarin $430 \mathrm{~A}$ stereochemistry at C3 is opposite to that found in myrmicarin $430 \mathrm{~A}$ (4).

\section{Results and Discussion}

\section{Brønsted Acid Promoted Dimerization Conditions}

The homodimerization of (+)-myrmicarin 215B (2) provided the basis for a potentially direct formation of myrmicarin 430A (4). The nature of the putative azafulvenium ion 
intermediates in the dimerization suggested that the rate or reversibility of each bond forming event may be influenced by solvent and counter ion effects. In order to address the regio- and stereochemical differences between the heptacycle we had obtained (20, Scheme 3 ) and the desired structure (10, Scheme 3$)$, we examined the acid promoted dimerization of (+)-myrmicarin 215B (2) under different reaction conditions (Table 1). Due to the known instability of myrmicarin 430A (4) and the observed sensitivity of heptacyclic derivatives such as 16, these experiments were monitored by in situ ${ }^{1} \mathrm{H}$ NMR and the structure of airsensitive final products confirmed by conversion to isolable derivatives. Unless strictly anhydrous conditions were required, the alcohol 15, which also undergoes TFA induced dimerization $^{\text {iia }}$ to isomyrmicarin 430A (17) via (+)-myrmicarin 215B (2), was employed in place of $\mathbf{2}$ due to its enhanced stability.

The stoichiometric trifluoroacetic acid (TFA) induced dimerization behavior of (+)myrmicarin 215B (2) was examined in methanol- $d_{4}$, THF- $d_{8}$, acetonitrile- $d_{3}$, and cyclohexane- $d_{12}$. In cyclohexane- $d_{12}$ the TFA promoted reactivity of (+)-myrmicarin $215 \mathrm{~B}$ $(2,0.0050 \mathrm{M})$ was similar to that we had observed in benzene- $d_{6} \cdot{ }^{\text {iia }}$ Namely, introduction of substoichiometric TFA promoted formation of the dimer $\mathbf{2 0}\left(\mathrm{X}^{-}=\mathrm{F}_{3} \mathrm{CCO}_{2}^{-}\right)$to approximately the same extent as the added acid (Table 1, entry 1), while rapid addition of superstoichiometric TFA yielded only pyrrole ring protonated products (Table 1, entry 2). Treatment of a THF- $d_{8}$ solution of alcohol $15(0.026 \mathrm{M})$ with trifluoroacetic acid (1.10 equiv) resulted in immediate and quantitative conversion to (+)-myrmicarin 215B (2), which was subsequently consumed to form the dimer $\mathbf{2 0}$ (Table 1 , entry 3 ). In this case, the dimerization was substantially slower than the dimerization in benzene- $d_{6}$ and only reached $80 \%$ conversion to $\mathbf{2 0}$ within 24 hours. In contrast, introduction of 1.10 equivalents of TFA to a solution of $\mathbf{1 5}$ in acetonitrile- $d_{3}(0.025 \mathrm{M})$ effected complete conversion to $\mathbf{2 0}$ within 30 seconds without a visible accumulation of (+)-myrmicarin 215B (2, Table 1, entry 4). In methanol- $d_{4}$, treatment of a solution of $15(0.026 \mathrm{M})$ with TFA (1.10 equiv) did not afford (+)-myrmicarin 215B (2) but resulted in complete formation of the C8 methanol adduct 21 within 30 seconds, which underwent $95 \%$ conversion to $\mathbf{2 0}$ within 45 minutes (Table 1, entry 5) without a visible accumulation of (+)-myrmicarin 215B (2). Significantly, no methanol adduct of dimeric products corresponding to trapping of putative intermediates (i.e., 9, Scheme 1A) or a methanol adduct of $\mathbf{2 0}$ were observed.

To investigate the influence of the ionic strength of the medium and the nature of the counterion on the acid induced chemistry of $\mathbf{2}$ we examined the effect of salt additives. While addition of TFA (1.10 equiv) to a solution of $\mathbf{1 5}$ in THF- $d_{8}(0.030 \mathrm{M})$ saturated with anhydrous lithium chloride $(\mathrm{LiCl})$ effected immediate conversion to (+)-myrmicarin $215 \mathrm{~B}$ (2), it substantially reduced the rate of the subsequent dimerization to $\mathbf{2 0}$, yielding a 1:1 ratio of (+)-myrmicarin 215B (2) to 20 after a period of 190 minutes (Table 1, entry 6), whereas the same ratio was obtained in 30 minutes in the absence of $\mathrm{LiCl}$. Consistent with our reported result for benzene- $d_{6},{ }^{2 \mathrm{a}}$ the acetic acid ( 0.20 equiv) treatment of a THF- $d_{8}$ solution of $15(0.054 \mathrm{M})$ saturated with $\mathrm{LiCl}$ effected complete conversion to (+)-myrmicarin 215B (2), but did not promote dimerization (Table 1, entry 7). By contrast, treatment of a THF- $d_{8}$ solution of (+)-myrmicarin $215 \mathrm{~B}(2,0.0065 \mathrm{M})$ saturated with $\mathrm{LiClO}_{4}$ as the salt additive with TFA (1.10 equiv) immediately generated a mixture of pyrrole-ring protonated tricyclic species and produced none of the heptacyclic iminium ion $\mathbf{2 0}$ (Table 1, entry 8).

To rule out possible influence of the trifluoroacetate anion in the dimerization process, a THF- $d_{8}$ solution of $15(0.013 \mathrm{M})$ saturated with $\mathrm{LiClO}_{4}$ was treated with $\mathrm{HClO}_{4}$ (1.10 equiv) in place of TFA. Consistent with the observed TFA induced reactivity (Table 1, entry 8), introduction of $\mathrm{HClO}_{4}$ instantly generated a mixture of ring protonated tautomers $\mathbf{2 4}$ (Table 1, entry 9). Exposure of a methanol- $d_{4}$ solution of $15(0.013 \mathrm{M})$ saturated with $\mathrm{LiClO}_{4}$ to $\mathrm{HClO}_{4}$ (1.10 equiv) afforded a mixture of ring protonated forms of the $\mathrm{C} 8$ methanol adduct 
21, which did not undergo dimerization (Table 1, entry 10). By contrast in an unsaturated methanolic solution of $\mathrm{LiClO}_{4}(1.6 \mathrm{M})$, portionwise addition of $\mathrm{HClO}_{4}(0.10$ equiv/portion) to a solution of $\mathbf{1 5}(0.026 \mathrm{M})$ effected complete formation of $\mathbf{2 1}$, followed by approximately proportional conversion to $\mathbf{2 0}$ (Table 1, entry 11).

In an effort to more efficiently trap possible electrophilic monomeric or dimeric intermediates present in equilibrium with the iminium ion 20, $p$-methylbenzenethiol $(0.60$ equiv) was introduced to a methanol- $d_{4}$ solution of $15(0.020 \mathrm{M})$ prior to portionwise substoichiometric addition of TFA. In this case, introduction of TFA resulted in immediate conversion to the $\mathrm{C} 8$-methanol adduct $\mathbf{2 1}$ followed by progressive formation of the tricyclic C8-sulfide 22, completely consuming the thiol additive (Table 1, entry 12). Concomitant dimerization of the remaining C8-methanol adduct to $\mathbf{2 0}$ consumed the remainder of the tricyclic substrate 15. Thiol adduct $\mathbf{2 2}$ was not subject to dimerization and no other adducts were observed during the reaction. ${ }^{\mathrm{v}}$ An attempt to use a weaker organic acid as a proton source and solvent by dissolving 15 in neat formic acid- $d_{2}$ resulted in immediate conversion to the corresponding epimeric formate esters $\mathbf{2 3}$, followed by slow conversion to a mixture of ring protonated tautomers $\mathbf{2 4}$, with approximately five percent (+)-myrmicarin 215B (2) visible throughout (Table 1, entry 13).

In none of these experiments did we visualize any dimeric species other than $\mathbf{2 0}\left(\mathrm{X}^{-}=\right.$ $\mathrm{F}_{3} \mathrm{CCO}_{2}{ }^{-}$or $\mathrm{ClO}_{4}{ }^{-}$, Table 1 ). While the use of strongly acidic conditions favoring ring protonation of (+)-myrmicarin 215B (2) prevented dimerization (Table 1, entries 7, 8, and 12), conditions that would enable neutral (+)-myrmicarin 215B (2) and an azafulvenium ion to coexist (Table 1, entries $2,3,4,5,6,11$, and 12) resulted in completely selective and quantitative formation of $\mathbf{2 0}$. Tricyclic $\mathrm{C} 8$-adducts were generated as equilibrating compounds in the presence of nucleophilic solvent (Table 1, entries 5 and 11) or irreversibly in the presence of stronger nucleophiles (Table 1, entry 12), however no nucleophilic adducts of the dimeric products were observed. The substantially reduced rate of dimerization in the presence of nucleophilic counterion under saturating conditions (Table 1, entry 6) suggests possible reversible interception of azafulvenium ion intermediates at either of the carbon-carbon bond forming steps (Scheme 1A). These observations collectively suggest that if a dimeric azafulvenium ion existed (i.e., 19, Scheme 3) it was a fleeting intermediate.

\section{Possible $\left[6 \pi_{a}+2 \pi_{s}\right]$ Cycloaddition Pathway}

The insensitivity of the dimerization reaction described above to variations in the reaction conditions prompted us to consider that the high diastereoselectivity and efficiency of the process might be a consequence of a concerted cycloaddition event instead of a stepwise ionic sequence (Scheme 4). Frontier molecular orbital (FMO) analysis of the proposed event revealed that a thermally allowed $\left[6 \pi_{\mathrm{a}}+2 \pi_{\mathrm{s}}\right]$ cycloaddition between the $E$-azafulvenium ion 25 and the $E$-alkene of (+)-myrmicarin 215B (2) could provide the isomyrmicarin 430A (17) structure with the correct stereochemistry in the cyclopentane ring (Scheme 4B). ${ }^{\text {iii }}$ In this sequence, association between the electron poor azafulvenium ion $\mathbf{2 5}$ and the electron rich (+)-myrmicarin 215B (2) would bring their convex faces together, whereupon a gearing effect would move the vinyl group of (+)-myrmicarin 215B (2) to the more sterically accessible side of azafulvenium ion $\mathbf{2 5}$. Interestingly, preliminary computations show that the Z-azafulvenium ion 8 is favored over the $E$-isomer 25 by $\sim 1.3 \mathrm{kcal} / \mathrm{mol}$, consistent with predictions based on molecular models and allylic strain considerations. ${ }^{\text {vi }}$ This would suggest that the observed dimerization may occur by equilibration of 8 and 25 accompanied by a faster cycloaddition involving the high energy isomer 25 .

A persuasive factor in our consideration of this $\left[6 \pi_{\mathrm{a}}+2 \pi_{\mathrm{s}}\right]$ cycloaddition was that an analogous process involving the $Z$-azafulvenium ion $\mathbf{8}$ would provide precisely the 
connectivity and stereochemistry found in myrmicarin 430A (4, Schemes 1B and 4C). Hence, mutual association of the convex faces of (+)-myrmicarin 215B (2) and the Zazafulvenium ion 8 would enable the approach of the C8-C9 alkene of (+)-myrmicarin 215B (2) syn-coplanar to the $\mathrm{C} 8$ methine of $Z$-azafulvenium ion $\mathbf{8}$, providing the iminium ion $\mathbf{1 0}$ via an antarafacial cycloaddition en route to myrmicarin 430A (4, Scheme 4C).

\section{Design and Synthesis of Conformationally Restricted Azafulvenium lon Precursors}

While it may be speculated that an enzyme mediated protonation event could be responsible for triggering a cycloaddition reaction and controlling the stereochemistry of an azafulvenium ion in the biosynthesis of myrmicarin 430A (4), we wished to examine this hypothesis experimentally using conformationally restricted substrates. If the dimerization was occurring through a concerted cycloaddition mechanism and the regio- and stereochemical outcome was dictated by the geometry of the azafulvenium ion, then a structure locked in the Z-geometry should undergo a cycloaddition with (+)- myrmicarin 215B (2) to provide the myrmicarin 430A (4) framework (Scheme 5). Therefore, we prepared the alcohols 26-27, in which a siloxy tether favors a $Z$-azafulvenium ion geometry upon ionization of the $\mathrm{C} 8$ alcohol (Scheme 5). The $Z$-azafulvenium ion 28, which is expected to give the desired myrmicarin $430 \mathrm{~A}(4)$ carbon skeleton in a $\left[6 \pi_{\mathrm{a}}+2 \pi_{\mathrm{s}}\right]$ manifold, can better accommodate the azafulvenium ion in the eight-membered ring than the corresponding $E$-azafulvenium ion 29. Additionally, sterically demanding alkyl groups on silicon would further favor formation and cycloaddition via the $Z$-azafulvenium ion $\mathbf{2 8}$.

The synthesis of the tethered azafulvenium ion precursor $\mathbf{4 0}$ commenced with oxidation of our previously reported $(R)$-alcohol $\mathbf{3 2} 2^{\mathrm{iib}}$ to the aldehyde $\mathbf{3 3}$ using 2-iodoxybenzoic acid in dimethylsulfoxide (Scheme 6). ${ }^{\text {vii }}$ Treatment of the aldehyde 33 with excess triisopropylsilyl trifluoromethanesulfonate in benzene at $50{ }^{\circ} \mathrm{C}$ for 4 hours effected $\mathrm{C} 8$-silyl enol ether formation and Friedel-Crafts cyclization to provided a $\mathrm{C} 3$-silyloxy pyrroloindolizine as a 6:1 C3-epimeric mixture. The acidic work up of this mixture and careful chromatographic separation yielded the diastereomerically pure ketone 36 in $81 \%$ overall yield. For largescale preparation, an alternative sequence was employed, which involved subjection of aldehyde 33 to triethylsilyl trifluoromethanesulfonate at $23{ }^{\circ} \mathrm{C}$ for $25 \mathrm{~min}$, exhaustive desilylation of the crude mixture, facile chromatographic separation of the $\mathrm{C} 3$ epimeric alcohols, and silylation of the major C3 epimer 35 (Scheme 6). In this series, the major C3Shydroxy pyrroloindolizine and related derivatives were found to be far more stable than the minor C $3 R$-hydroxy series and were thus employed in subsequent steps. Hydroxylation of the lithium enolate of $\mathbf{3 6}$ with Davis oxaziridine ${ }^{\text {viii }}$ generated the $\alpha$-keto alcohol 37 in $85 \%$ yield as a 4:1 mixture of chromatographically separable C8-epimers.ix Unveiling ${ }^{\mathrm{X}}$ the $\mathrm{C} 3$ alcohol allowed the introduction of the desired [1,3,2]-dioxasilocine substructure of ketone 39. Reduction of the $\mathrm{C} 8$ ketone provided the $\mathrm{C} 8$-alcohol 40 (10:1 dr, major shown, Scheme $6)$, which was obtained in diastereomerically pure form after flash column chromatography.

To investigate the heterodimerization event of interest (Scheme 5) we required a means of generating the putative azafulvenium ion from the conformationally restricted precursor $\mathbf{4 0}$ without activation of (+)-myrmicarin 215B (2). To avoid rapid self-dimerization of (+)myrmicarin 215B (2) in the presence of Brønsted acid, we relied on Lewis acid activation of the $\mathrm{C} 8$-alcohol 40. As validation of this strategy, under optimal conditions, treatment of the tricyclic C8-alcohol 15 (1:1 mixture of C8 alcohols) with scandium trifluoromethanesulfonate $\left(\mathrm{ScOTf}_{3}, 0.20\right.$ equiv) in the presence of the $E$-thiolketene acetal 41 (2.00 equiv, $E(O): Z(O)=20: 1)^{x i}$ provided the thiolester 42 in $85 \%$ yield (Equation 1). ${ }^{\text {xii }}$

Based on these observations we sought to substitute an electron rich vinyl pyrroloindolizine derivative in place of the thiolketene acetal $\mathbf{4 1}$ to probe the cycloaddition hypothesis outlined in Scheme 5. In situ ${ }^{1} \mathrm{H}$ NMR monitoring showed that portionwise addition of 0.40 
equivalents of $\mathrm{Sc}(\mathrm{OTf})_{3}$ to a mixture of (+)-myrmicarin $215 \mathrm{~B}(2)$ and conformationally restricted azafulvenium ion precursor $40(2: 40,2: 1)$ in acetonitrile- $d_{3}$ selectively and completely produced a single new heterodimeric species ( $\geq 90 \%$ by $\left.{ }^{1} \mathrm{H} N M R\right)^{x i i i}$ with no visible formation of any isomyrmicarin $430 \mathrm{~A}$ derivatives. This product proved to be slightly more stable to isolation than isomyrmicarin 430A (17). Isolation and structural analysis of this new air-sensitive heterodimerization product by a combination of 2D NMR techniques established the structure of the heterodimer $\mathbf{4 3}$ (Equation 2), which possessed connectivity and stereochemistry consistent with that of isomyrmicarin 430A (17, Scheme 2). Strong C1$\mathrm{H} / \mathrm{C} 4-\mathrm{H}$ NOESY correlations confirmed the connectivity of the cyclopentane ring, while $\mathrm{C} 1-\mathrm{H} / \mathrm{C} 10^{\prime}-\mathrm{H}$ and $\mathrm{C} 2-\mathrm{H} / \mathrm{C} 3-\mathrm{H}$ correlations secured the stereochemistry at $\mathrm{C} 1, \mathrm{C} 2$, and $\mathrm{C} 3$. A C3-H/C9-H correlation confirmed that the $\mathrm{C} 9$ stereochemistry of the alcohol $\mathbf{4 0}$ had been retained.

While molecular model analysis of the $E$-azafulvenium ion $\mathbf{2 9}$ (Scheme 5) en route to the isomyrmicarin $430 \mathrm{~A}$ framework indicated that this compound was significantly more strained than the corresponding $Z$-azafulvenium ion $\mathbf{2 8}$, it remained possible that $\mathbf{2 9}$ could be accessed from (9S)-alcohol $\mathbf{4 0}$ (Equation 2) as a high energy intermediate. By contrast, a similar analysis of the C9-epimer of $\mathbf{4 0}$ (i.e., 27, Scheme 5) clearly showed that the corresponding $E$-azafulvenium ion derivative would suffer a significant allylic strain that was absent in the desired $Z$-azafulvenium ion. Based on the expectation that 27 (Scheme 5) would provide greater preference for formation of $\mathbf{2 8}$ over $\mathbf{2 9}$, we embarked on the preparation of the $\mathrm{C} 9$-epimer of $\mathbf{4 0}$ (Scheme 7). To garner significant quantities of the required C9-epimer, the $\mathrm{C} 9$-alcohol $\mathbf{3 7}$ was subjected to Mitsunobu inversion ${ }^{\text {xiv }}$ with $p$ nitrobenzoic acid (Scheme 7) followed by hydrolysis and desilylation to provide the diol $\mathbf{4 5}$. While introduction of the tether had proceeded efficiently with the C9 epimer 38 (Scheme 6), exposure of diol $\mathbf{4 5}$ to the same conditions provided only $29 \%$ of the desired product $\mathbf{4 6}$ along with a mixture of C9- and C3-mono-and bis-silylated products (Scheme 7), suggesting a more challenging formation of the epimeric [1,3,2]-dioxasilocine substructure. Separation of $\mathbf{4 6}$ from the mixture and desilylation of the undesired products allowed recycling to access the target compound 46. As another testament to the conformational and reactivity differences between the $\mathrm{C} 9$-epimers of these pyrroloindolizines, lithium aluminum hydride reduction of the ketone $\mathbf{4 6}$ afforded the unstable $\mathrm{C} 3, \mathrm{C} 8, \mathrm{C} 9$-triol derivative as the major product, along with the desired alcohol $\mathbf{4 7}$ and recovered starting material. Despite these challenges, the desired azafulvenium ion precursor $\mathbf{4 7}$ was obtained in low yield as a single diastereomer (Scheme 7) in this sequence, allowing its examination as an azafulvenium ion precursor.

In the key heterodimerization event, exposure of an equal mixture of (+)-myrmicarin 215B (2) and alcohol 47 to the conditions described previously (Equation 2) completely and exclusively afforded a new heterodimeric product (Scheme 8 ) in $\geq 90 \%$ yield by ${ }^{1} \mathrm{H} \mathrm{NMR}^{\mathrm{xv}}$. Reciprocal $\mathrm{C} 4 / \mathrm{C} 1-\mathrm{H}$ and $\mathrm{C} 1 / \mathrm{C} 4-\mathrm{H}$ HMBC correlations revealed that the dimer 49 again had the same connectivity as isomyrmicarin 430A (Scheme 8). C1-H/C10'-H and C2-H/C3-H NOESY correlations revealed the stereochemistry at $\mathrm{C} 1, \mathrm{C} 2$, and $\mathrm{C} 3$ was identical to that of 43 and isomyrmicarin 430A (17). Finally, $\mathrm{C} 1-\mathrm{H} / \mathrm{C} 9-\mathrm{H}$ and $\mathrm{C} 9-\mathrm{H} / \mathrm{C} 10^{\prime}-\mathrm{H}$ correlations confirmed that the heterodimers $\mathbf{4 9}$ and $\mathbf{4 3}$ differed only in their C9-stereochemistry. It should be noted that the prohibitively strained $E$-azafulvenium ion $\mathbf{4 8 b}$ is an unlikely intermediate in this dimerization reaction. Additionally, an antarafacial $\left[6 \pi_{\mathrm{a}}+2 \pi_{\mathrm{s}}\right]$ cycloaddition involving a Z-azafulvenium ion and (+)-myrmicarin 215B (2) would furnish a product with the stereochemistry at $\mathrm{C} 3$ opposite to that found in 49 . These factors taken together suggest that the observed heterodimerization does not proceed via a concerted cycloaddition. Instead, the structure of condensation product 49 is more consistent with a stepwise addition of (+)-myrmicarin 215B (2) to the azafulvenium ion 48a, followed by attack of the pyrrole at to the resulting electrophilic $\mathrm{C} 1$ (Scheme 8). While these results did 
not rule out a concerted $\left[6 \pi_{\mathrm{a}}+2 \pi_{\mathrm{s}}\right]$ pathway for the formation of either isomyrmicarin $430 \mathrm{~A}$ (17) or myrmicarin 430A (4), they did implicate significant obstacles in implementation of a single step cyclopentannulation employing these azafulvenium ions towards the synthesis of the complex myrmicarins.

\section{A Directed Heterodimerization Approach to Functional and Dimeric Pyrroloindolizines}

To overcome the inherent propensity to form the isomyrmicarin substructure in the observed homo- and hetero-dimerization reactions we required a means of decoupling the two bondforming events of the cyclopentannulation. Hence, we sought the selective electrophilic activation of a pyrroloindolizine derivative $\mathbf{5 0}$ (Scheme 9) followed by nucleophilic trapping by 51 to provide the $\mathrm{C} 2-\mathrm{C} 3$ bond in the heterodimer $\mathbf{5 3}$. We reasoned that the introduction of a 'blocking' functional group (Y) at C8 of the pyrroloindolizine 51 (Scheme 9) should either prevent an intramolecular Friedel-Crafts addition to directly give the desired hexacycle 55, or promote cleavage of the $\mathrm{C} 1-\mathrm{C} 3 \mathrm{~b}$ bond in an isomyrmicarin derivative $\mathbf{5 4}$ (Scheme 9). Introduction of a functional handle at C9 of the electrophilic precursor would enable adjustment of the stereochemistry at $\mathrm{C} 3$ after dimerization. This strategy could also benefit from the use of tethered azafulvenium ions (i.e., as $\mathbf{4 0}$ and $\mathbf{4 7}$ ) to secure dimeric products with a high level of diastereoselection. Significantly, this approach would provide access to functional hexacyclic derivatives pertinent to alternative late-stage cyclopentannulation chemistries, such as free-radical mediated cyclization as suggested by our proposed radical dimerization of pyrroloindolizines (Scheme 1C). With these considerations in mind, we investigated the directed heterodimerization of pyrroloindolizine derivatives.

The $(R)$-ketone $\mathbf{5 6}^{\mathrm{iib}}$ served as a versatile building block for the preparation of the necessary functional pyrroloindolizines (Scheme 10). The silyl enol ether 57 was prepared quantitatively and exclusively as the Z-isomer by treatment of the ketone $\mathbf{5 6}$ with triisopropyl trifluoromethanesulfonate in the presence of triethylamine at low temperature. Hydroxylation of the lithium enolate of $\mathbf{5 6}$ followed by O-methylation with methyl iodide and sodium hydride provided the C9-methoxy ketopyrroloindolizine $\mathbf{5 9}$ as a mixture of C9epimers (5:2). As in the synthesis of ketone 37, strict control over the stoichiometry of the oxidant during the hydroxylation step was necessary to avoid further oxidation of the product 58. Inspired by our earlier studies, we explored the direct electrophilic activation of the vinylogous amide 58 in the presence of silyl enol ether 57. Despite pronounced Brønsted acid sensitivity, the silyl enol ether $\mathbf{5 7}$ served as a superb nucleophile in trapping the activated derivative of amide 59. In this event, treatment of an equal mixture of the $\alpha$ methoxy ketone $\mathbf{5 9}$ and the silyl enol ether $\mathbf{5 7}$ with trifluoromethanesulfonic anhydride in the presence of 2,6-di-tbutyl-4-methylpyridine provided the methyl vinyl ether $\mathbf{6 0}$ in $70 \%$ yield as a mixture of diastereomers. Hydrolysis of $\mathbf{6 0}$ to the diketone $\mathbf{6 1}$ was achieved by exposure to pyridinium $p$-toluenesulfonate in benzene-acetonitrile-water at $23{ }^{\circ} \mathrm{C}$ under strictly oxygen-free conditions. ${ }^{\mathrm{xvi}}$ Importantly, this two-step sequence provides a directed condensation between two pyrroloindolizine fragments (i.e., 57 and 59) while at the same time securing the $\mathrm{C} 1$-vinylogous amide needed for activation and cyclopentannulation, in addition to the C9-ketone for control of C3-stereochemistry.

In parallel to these efforts, we investigated the use of conformationally restricted pyrroloindolizine electrophiles to gain stereochemical control in the heterodimerization reaction. For example, when the azafulvenium precursor $\mathbf{4 0}$ is treated with catalytic scandium trifluromethanesulfonate in the presence of the silyl enol ether 57 (1.56 equiv), heterodimer $\mathbf{6 2}$ is obtained in 73\% yield as a 5:1 mixture of two diastereomers (Equation 3). Key C2-H/C4-H and C9-H/C3-H NOE correlations clearly secure the structure of the major diastereomer as shown in Equation 3. With these promising initial results, our current efforts are focused on merging of the fragment assembly strategy illustrated in Scheme 10 
with the use of conformationally biased azafulvenium ion precursors (i.e., $\mathbf{4 0}$ and $\mathbf{4 7}$ ) to access functional and dimeric pyrroloindolizines with enhanced levels of diastereoselection. Additionally, the $\mathrm{C} 1$-carbonyl of dimeric pyrroloindolizines allows investigation of freeradical or azafulvenium ion mediated pathways to introduce the $\mathrm{C} 1-\mathrm{C} 8 \mathrm{~b}$ bond found in complex myrmicarins guided by the hypotheses outlined in Scheme 1.

\section{Conclusions}

Vinyl pyrroloindolizines possess a unique structure that predisposes them to highly efficient activation at $\mathrm{C} 8$. This mode of activation enables a variety of activated pyrroloindolizine derivatives to undergo reaction with neutral pyrroloindolizines to afford the corresponding dimeric structures. In an ionic manifold, Brønsted acid activation of the natural alkaloid (+)myrmicarin 215B (2) leads to highly efficient and stereoselective homodimerization to form the heptacyclic isomyrmicarin 430A (17) under a variety of reaction conditions. Likewise, Lewis acid activation of the conformationally restricted azafulvenium precursors $\mathbf{4 0}$ or $\mathbf{4 7}$ in the presence of (+)-myrmicarin 215B (2) affords heptacyclic derivatives $\mathbf{4 3}$ and $\mathbf{4 9}$, respectively-structures that are consistent with a highly efficient non-concerted ionic heterodimerization process. Through strategic design of the pyrroloindolizine species involved in the dimerization (e.g. $\mathbf{5 7}$ and 59), the two bond forming events of the cyclopentannulation can be decoupled, providing hexacyclic dimers en route to the complex myrmicarin alkaloid structures. Importantly, dimeric products such as $\mathbf{6 1}$ and $\mathbf{6 2}$ contain functional groups needed to investigate alternative radical or ionic pathways to control the regio- and stereochemistry of the cyclopentannulation process. While representing a concise route to the complex myrmicarins, the dimerization of these pyrroloindolizines offers insight with potential relevance to their biosynthesis. Such considerations continue to guide our study of these structurally fascinating alkaloids.

\section{Experimental Section}

\section{1-(1-Ethyl-3,4,4a,5,6,7-hexahydro-pyrrolo[2,1,5-cd]indolizin-2-yl)-2-methoxy-propan-1-one} (59)

Sodium hydride (60\% dispersion in mineral oil, $56.0 \mathrm{mg}, 1.40 \mathrm{mmol}, 2.00$ equiv) was added in a single portion to an anhydrous solution of the $\alpha$-hydroxy ketone $\mathbf{5 8}(173 \mathrm{mg}, 700 \mu \mathrm{mol}$, 1 equiv) and methyl iodide ( $131 \mu \mathrm{L}, 2.10 \mathrm{mmol}, 3.00$ equiv) in dimethylformamide (4.75 $\mathrm{mL}$ ) at $23{ }^{\circ} \mathrm{C}$. The resulting suspension gradually became a clear and colouress solution within $5 \mathrm{~min}$. After $1 \mathrm{~h}$, the solution was slowly poured into a mixture of water and saturated aqueous ammonium chloride solution $(1: 1,20 \mathrm{~mL})$ causing vigorous gas evolution, and this mixture was diluted with a solution of ethyl acetate and hexanes $(3: 2,25 \mathrm{~mL})$. The aqueous phase was separated and extracted with ethyl acetate-hexanes $(3: 2,4 \times 20 \mathrm{~mL})$. The combined organic phases were washed with brine $(15 \mathrm{~mL})$, were dried over anhydrous sodium sulfate, were filtered, and were concentrated under reduced pressure. The residue was purified by flash column chromatography on silica gel (eluent: $2.5 \%$ triethylamine and $37.5 \%$ ethyl acetate in hexanes, diameter: $3.0 \mathrm{~cm}$, height: $10 \mathrm{~cm}$ ) to afford the $\alpha$-methoxy ketone 59 (173 mg, 94\%, mixture of C9 epimers, 9:5 dr) as a colorless oil. ${ }^{1} \mathrm{H}$ NMR (500 $\left.\mathrm{MHz}, \mathrm{C}_{6} \mathrm{D}_{6}, 20^{\circ} \mathrm{C}, 9: 5 \mathrm{dr}\right): 4.30(\mathrm{q}, J=6.8 \mathrm{~Hz}, 1 \mathrm{H}), 4.28(\mathrm{q}, J=6.7 \mathrm{~Hz}, 1 \mathrm{H}), 2.94-3.16(\mathrm{~m}$, $6 \mathrm{H}), 2.71(\mathrm{dd}, J=15.8,8.1 \mathrm{~Hz}, 1 \mathrm{H}), 2.70(\mathrm{dd}, J=15.7,8.1 \mathrm{~Hz}, 1 \mathrm{H}), 2.50$ (ddd, $J=16.9$, $11.8,6.7 \mathrm{~Hz}, 1 \mathrm{H}), 2.70(\mathrm{dd}, J=15.7,8.1 \mathrm{~Hz}, 1 \mathrm{H}), 2.50(\mathrm{ddd}, J=16.0,10.5,5.8 \mathrm{~Hz}, 1 \mathrm{H})$, 2.50 (ddd, $J=16.0,10.7,5.2 \mathrm{~Hz}, 1 \mathrm{H}), 2.38$ (ddd, $J=16.5,6.4,0.9 \mathrm{~Hz}, 2 \mathrm{H}$ ), 2.13 (ddd, $J=$ $16.9,11.8,6.7 \mathrm{~Hz}, 1 \mathrm{H}), 2.12$ (ddd, $J=16.4,12.1,6.3 \mathrm{~Hz}, 1 \mathrm{H}), 1.73-1.79(\mathrm{~m}, 2 \mathrm{H}), 1.47-1.55$ $(\mathrm{m}, 2 \mathrm{H}), 1.45-1.49(\mathrm{~m}, 12 \mathrm{H}), 1.29-1.42(\mathrm{~m}, 4 \mathrm{H}), 0.99-1.20(\mathrm{~m}, 2 \mathrm{H}), 0.62-0.72(\mathrm{~m}$, 2H). ${ }^{13} \mathrm{C}$ NMR (125.8 MHz, $\left.\mathrm{C}_{6} \mathrm{D}_{6}, 20^{\circ} \mathrm{C}, 9: 5 \mathrm{dr}\right): 195.5,195.4,137.5,137.5,126.8,126.8$, 121.1, 121.0, 115.3, 115.1, 81.3, 81.1, 56.6, 56.6, 56.1, 56.1, 36.2, 36.2, 29.7, 29.6, 29.3, $29.1,19.0,18.5,16.4,16.3,22.6,22.5,20.3,20.3,19.9,19.9$. FTIR (neat) $\mathrm{cm}^{-1}: 2929$ (s), 
1651 (s, C=O), 1494 (s), 1320 (m), 1037 (w). HRMS-EI (m/z): calcd for $\mathrm{C}_{16} \mathrm{H}_{23} \mathrm{NNaO}_{2}$ [M $+\mathrm{Na}]^{+}: 284.1621$, found: 284.1626 . TLC $\left(2.5 \% \mathrm{Et}_{3} \mathrm{~N}, 17.5 \% \mathrm{EtOAc}, 20 \% \mathrm{CH}_{2} \mathrm{Cl}_{2-}\right.$ hexanes), $R f: 0.26$ (UV, CAM).

\section{Z-4-Ethyl-3-[1-(triisopropyl-silanyloxy)-propenyl]-1,2,5,6,7,7a-hexahydro-pyrrolo[2,1,5- co] indolizine (57)}

Triisopropylsilyl trifluoromethanesulfonate $(24.2 \mu \mathrm{L}, 89.9 \mu \mathrm{mol}, 1.05$ equiv) was added dropwise to an anhydrous solution of ketone $\mathbf{5 6}(19.8 \mathrm{mg}, 85.6 \mu \mathrm{mol}, 1$ equiv) and triethylamine $\left(59.7 \mu \mathrm{L}, 428 \mu \mathrm{mol}, 5.00\right.$ equiv) in dichloromethane $(1.70 \mathrm{~mL})$ at $-45^{\circ} \mathrm{C}$ such that the intense yellow color produced upon adding each drop had completely disappeared before the next drop was added. After complete addition of triisopropylsilyl trifluoromethanesulfonate, an ice-cold solution of saturated aqueous sodium bicarbonate solution $(3.5 \mathrm{~mL})$ was added. The reaction flask was immediately removed from the cooling bath and the mixture was diluted with an additional portion of ice-cold saturated aqueous sodium bicarbonate solution $(1.5 \mathrm{~mL})$ and diethyl ether $(7.5 \mathrm{~mL})$. The aqueous layer was separated and extracted with diethyl ether $(2 \times 6 \mathrm{~mL})$. The combined organic phases were washed with ice-cold brine $(3.5 \mathrm{~mL})$, were dried over anhydrous sodium sulfate, were filtered, and were concentrated under reduced pressure to afford the pure Z-triisopropylsilyl enol ether $57(33.2 \mathrm{mg}, 100 \%)$ as a colorless oil. ${ }^{1} \mathrm{H}$ NMR $\left(500 \mathrm{MHz}, \mathrm{C}_{6} \mathrm{D}_{6}, 20{ }^{\circ} \mathrm{C}\right): 4.91$ (q, $1 \mathrm{H}, J=6.7 \mathrm{~Hz}$ ), 3.31 (tdd, $1 \mathrm{H}, J=10.7,5.5,3.8 \mathrm{~Hz}), 2.65-2.88(\mathrm{~m}, 4 \mathrm{H}), 2.57$ (ddd, $1 \mathrm{H}, J=$ $16.3,6.0,0.7 \mathrm{~Hz}$ ), 2.37 (ddd, $1 \mathrm{H}, J=16.3,11.8,6.9 \mathrm{~Hz}), 1.99(\mathrm{dt}, J=11.6,5.5 \mathrm{~Hz}, 1 \mathrm{H})$, $1.92(\mathrm{~d}, 3 \mathrm{H}, J=6.7 \mathrm{~Hz}), 1.66$ (ddddd, $1 \mathrm{H}, J=13.7,6.7,4.1,2.7,0.7 \mathrm{~Hz}), 1.49-1.61(\mathrm{~m}$, $2 \mathrm{H}), 1.29-1.39(\mathrm{~m}, 1 \mathrm{H}), 1.37(\mathrm{t}, 3 \mathrm{H}, J=7.5 \mathrm{~Hz}), 0.82(\mathrm{tdd}, 1 \mathrm{H}, J=12.7,10.7,2.7 \mathrm{~Hz}) .{ }^{13} \mathrm{C}$ NMR $\left(125.8 \mathrm{MHz}, \mathrm{C}_{6} \mathrm{D}_{6}, 20^{\circ} \mathrm{C}\right): 148.2,129.3,121.7,119.1,116.7,104.6,55.6,37.5,30.4$, 25.9, 23.0, 21.1, 19.9, 18.7, 16.2, 14.3, 12.3. FTIR (neat): 2943 (s), 2865 (s), 1661 (s, C=C), 1463 (s), 1060 (s). HRMS-EI $(\mathrm{m} / \mathrm{z})$ : calcd for $\mathrm{C}_{24} \mathrm{H}_{42} \mathrm{NOSi}[\mathrm{M}+\mathrm{H}]^{+}: 388.3030$, found: 388.3046. TLC (alumina gel, 10\% EtOAc-hexanes), Rf: 0.72 (UV, CAM).

\section{1,3-Bis-(1-ethyl-3,4,4a,5,6,7-hexahydro-pyrrolo[2,1,5-cd]indolizin-2-yl)-4-methoxy-2-methyl- pent-3-en-1-one (60)}

A solution of 2,6-di-tert-butyl-4-methylpyridine ( $377 \mathrm{mg}, 1.84 \mathrm{mmol}, 5.00$ equiv) in dichloromethane $(500 \mu \mathrm{L}+250 \mu \mathrm{L}$ rinse $)$ was added to an anhydrous solution of triisopropylsilyl enol ether $\mathbf{5 7}$ ( $160 \mathrm{mg}, 413 \mu \mathrm{mol}, 1.13$ equiv) and the $\alpha$-methoxyketone $\mathbf{5 9}$ $(96.0 \mathrm{mg}, 367 \mu \mathrm{mol}, 1$ equiv, mixture of $\mathrm{C} 9$ epimers, $5: 2 \mathrm{dr})$ in dichloromethane $(2.50 \mathrm{~mL})$ at $23{ }^{\circ} \mathrm{C}$ and the resulting solution was cooled to $-78^{\circ} \mathrm{C}$. Trifluoromethanesulfonic anhydride ( $31.0 \mu \mathrm{L}, 184 \mu \mathrm{mol}, 0.500$ equiv) was added dropwise via syringe, causing the solution to become opaque and deep burgundy within 90 seconds. After $30 \mathrm{~min}$, three additional portions of trifluoromethanesulfonic anhydride ( $31.0 \mu \mathrm{L}, 184 \mu \mathrm{mol}, 0.500$ equiv) were added in $30 \mathrm{~min}$ intervals. When $40 \mathrm{~min}$ had elapsed after the last addition, saturated aqueous sodium bicarbonate solution $(1.5 \mathrm{~mL})$ was added and the aqueous phase was allowed to freeze ( $<5$ seconds), and the reaction flask was removed from the cooling bath. After approximately $5 \mathrm{~min}$ at $23^{\circ} \mathrm{C}$ the biphasic mixture was diluted with ethyl acetate (15 $\mathrm{mL})$ and an additional portion of saturated aqueous sodium bicarbonate solution $(5 \mathrm{~mL})$ and water $(1.5 \mathrm{~mL})$. The aqueous layer was separated and extracted with ethyl acetate $(3 \times 7.5$ $\mathrm{mL})$. The combined aqueous phases were washed with brine $(5 \mathrm{~mL})$, were dried over anhydrous sodium sulfate, and were filtered. Benzene $(5 \mathrm{~mL})$ was added to the organic phase and it was concentrated to a deep burgundy solution (final volume approximately 250 $\mu \mathrm{L}$ ). This sample was directly subjected to flash column chromatography on silica gel (eluent: $2 \%$ triethylamine, $2 \%$ ethyl acetate, and 5\% dichloromethane in hexanes, then flushed with $5 \%$ triethylamine in ethyl acetate to recover any remaining $\alpha$-methoxy ketone, diameter: $3.0 \mathrm{~cm}$, height: $25 \mathrm{~cm})$ to afford the desired heterodimer $\mathbf{6 0}(142 \mathrm{mg}, 84 \%$, mixture of stereoisomers, 3:2:1 dr) as a pale orange oil. ${ }^{1} \mathrm{H}$ NMR ${ }^{1} \mathrm{H}$ NMR $(500 \mathrm{MHz}$, 
$\left.\mathrm{C}_{6} \mathrm{D}_{6}, 20^{\circ} \mathrm{C}, 3: 2: 1 \mathrm{dr}\right): 4.06(\mathrm{q}, J=7.0 \mathrm{~Hz}, 1 \mathrm{H}), 4.04(\mathrm{q}, J=7.0 \mathrm{~Hz}, 1 \mathrm{H}), 4.04(\mathrm{q}, J=7.0 \mathrm{~Hz}$, $1 \mathrm{H}), 3.24(\mathrm{~s}, 3 \mathrm{H}), 3.24(\mathrm{~s}, 3 \mathrm{H}), 3.24(\mathrm{~s}, 3 \mathrm{H}), 3.09-3.46(\mathrm{~m}, 6 \mathrm{H}), 2.30-3.09(\mathrm{~m}, 36 \mathrm{H}), 2.14$ $2.25(\mathrm{~m}, 6 \mathrm{H}), 2.09(\mathrm{~s}, 3 \mathrm{H}), 2.07(\mathrm{~s}, 3 \mathrm{H}), 2.03(\mathrm{~s}, 3 \mathrm{H}), 1.75(\mathrm{~d}, J=7.0 \mathrm{~Hz}, 3 \mathrm{H}), 1.74(\mathrm{~d}, J=$ $7.0 \mathrm{~Hz}, 3 \mathrm{H}), 1.72(\mathrm{~d}, J=7.0 \mathrm{~Hz}, 3 \mathrm{H}), 1.33-1.97(\mathrm{~m}, 24 \mathrm{H}), 1.15-1.30(\mathrm{~m}, 18 \mathrm{H}), 0.73-1.02$ (m, 6H). ${ }^{13} \mathrm{C}$ NMR $\left(125.8 \mathrm{MHz}, \mathrm{C}_{6} \mathrm{D}_{6}, 20{ }^{\circ} \mathrm{C}, 3: 2: 1 \mathrm{dr}\right): 196.0,195.6,195.9,150.7,150.6$, $150.5,136.5,136.3,136.3,130.6,130.3,129.6,126.8,126.6,126.4,126.4,126.4,126.4$, 123.0, 122.9, 122.8, 120.3, 120.3, 120.2, 118.2, 118.2, 118.1, 117.9, 117.8, 117.7, 113.2, 113.1, 112.4, 56.6, 56.6, 56.5, 56.1, 56.1, 55.9, 55.8, 55.7, 55.7, 48.7, 48.6, 47.9, 37.5, 37.4, $37.4,36.6,36.5,36.3,30.6,30.4,30.3,30.1,30.0,30.0,28.1,28.0,27.6,26.7,26.5,26.3$, $23.4,23.4,23.3,22.9,22.9,22.8,21.9,21.8,21.8,20.1,20.1,20.0,20.0,20.0,20.0,20.0$, $20.0,19.9,17.9,17.6,17.6,16.5,16.1,16.0,16.0,15.8,15.8,15.6,15.4,15.2$. FTIR (neat) $\mathrm{cm}^{-1}$ : 2928 (s), 1643 (s, C=O), $1496(\mathrm{~s}), 1427(\mathrm{~s}), 1321(\mathrm{~m})$. HRMS-EI $(\mathrm{m} / \mathrm{z})$ : calcd for $\mathrm{C}_{31} \mathrm{H}_{43} \mathrm{~N}_{2} \mathrm{O}_{2}[\mathrm{M}+\mathrm{H}]^{+}: 475.3319$, found: 475.3316. TLC (Et ${ }_{3} \mathrm{~N}$-pretreated silica gel, $1 \%$ $\mathrm{Et}_{3} \mathrm{~N}, 9 \%$ EtOAc-hexanes), Rf: 0.31 (UV, CAM).

\section{Supplementary Material}

Refer to Web version on PubMed Central for supplementary material.

\section{Acknowledgments}

M.M. is a Firmenich Assistant Professor of Chemistry and a Beckman Young Investigator. A.E.O. acknowledges a Novartis Graduate Fellowship. We thank Professor Robert G. Griffin and Dr. Tony Bielecki for use of a high field instrument at the MIT-Harvard Center for Magnetic Resonance (EB-002026). We thank Dr. Li Li for obtaining mass spectrometric data at the Department of Chemistry's Instrumentation Facility, Massachusetts Institute of Technology. We thank Dr. Timothy E. Barder in the Buchwald group and Mr. Omar K. Ahmad for their assistance with DFT calculations. We are grateful for financial support by NIH-NIGMS (GM074825).

\section{References}

i. (a) Francke W, Schröder F, Walter F, Sinnwell V, Baumann H, Kaib M. Liebigs Ann. Chem 1995:965-977. (b) Schröder F, Franke S, Francke W. Tetrahedron 1996;52:13539-13546. (c) Schröder F, Sinnwell V, Baumann H, Kaib M. Chem. Commun 1996:2139-2140. (d) Schröder F, Sinnwell V, Baumann H, Kaib M, Francke W. Angew. Chem., Int. Ed 1997;36:77-80. (e) Schröder F, Francke W. Tetrahedron 1998;54:5259-5264.

ii. (a) Ondrus AE, Movassaghi M. Tetrahedron 2006;62:5287-5297. [PubMed: 20640170] (b) Movassaghi M, Ondrus AE. Org. Lett 2005;7:4423-4426. [PubMed: 16178549]

iii. For FMO analysis of cycloadditions involving fulvenes, see: (a) Houk KN, George JK, Duke RE Jr. Tetrahedron 1974;30:523-533. (b) Houk KN. Acc. Chem. Res 1975;8:361-369. For computational analysis of fulvene FMOs, see: (c) Scott AP, Agranat I, Biedermann UP, Riggs NV, Radom L. J. Org. Chem 1997;62:2026-2038. [PubMed: 11671506] (d) Havenith RWA, Fowler PW, Steiner E. J. Chem. Soc. Perkin Trans. 2 2002;2:502-507. For formal [6+2] cycloadditions involving fulvene species, see: (e) Hong B-C, Shr Y-J, Wu J-L, Gupta AK, Lin KJ. Org. Lett 2002;4:2249-2252. [PubMed: 12074679] (f) Hafner K, Suda M. Angew. Chem. Int. Ed 1976;15:314-315.

iv. For a review on the chemistry of $C$-vinyl pyrrole derivatives, see: (a) Trofimov BA, Sobenina LN, Demenev AP, Mikhaleva AI. Chem. Rev 2004;104:2481-2506. [PubMed: 15137797] For general reviews on the chemistry of pyrroles, see: (b) Pelkey, ET. Progress in Heterocyclic Chemistry. Gribble, G.; Joule, J., editors. Vol. Vol. 17. Oxford, UK: Publisher: Elsevier Ltd; 2005. p. 109-141. Five- Membered Ring Systems: Pyrroles and Benzo Derivatives (c) Jones, A., editor. Pyrroles. New York: Wiley; 1990. (d) Alan, JR.; Bean, GP. The Chemistry of Pyrroles. London: Academic Press; 1977. (e) Baltazzi E, Krimen LI. Chem. Rev 1963;63:511-556.

v. Heating a solution of this mixture of dimer 20 and sulfide $22\left(55^{\circ} \mathrm{C}\right)$ resulted only in decomposition of the dimer. 
vi. DFT calculations performed using B3LYP/6-31G; gas phase, energy minimized structure of the free azafulvenium ions.

vii. Frigerio M, Santagostino M. Tetrahedron Lett 1994;35:8019-8022.

viii. Davis FA, Vishwakarma LC, Billmers JG, Finn J. J. Org. Chem 1984;49:3241-3243.

ix. Attempts to introduce the $\mathrm{C} 9$-alcohol via the $\mathrm{C} 8-\mathrm{C} 9$ silyl enol ether by dihydroxylation or epoxidation failed, likely as a result of the sensitivity of the vinyl pyrrole nucleus toward oxidation.

$\mathrm{x}$. The presence of a free C3-hydroxyl group significantly complicated the introduction of the C9hydoxyl group.

xi. For the synthesis of $E(\mathrm{O})$ - and $Z(\mathrm{O})$-thiolketene acetal 41, seeEvans DA, Burgey CS, Kozlowski MC, Tregay SW. J. Am. Chem. Soc 1999;121:686-699. and DeRoy PL, Charette AB. Org. Lett 2003;5:4163-4165. [PubMed: 14572275] respectively

xii. Under the conditions described above, thiolester $\mathbf{4 2}$ was obtained as an inseparable mixture of diastereomers (dr, 1:17:2.5:13). Use of the corresponding $Z$-thiolketeneacetal (2.00 equiv, $E(\mathrm{O}): Z(\mathrm{O})=1: 12$ ) gave $\mathbf{4 2}$ with a diminished level of diastereoselection (dr, 1:2.1:1.4:2.3).

xiii. In situ ${ }^{1} \mathrm{H}$ NMR monitoring of the homogeneous reaction mixture showed complete consumption of $\mathbf{4 0}$ with concomitant formation of $\mathbf{4 3}$ and no other visible compounds except remaining excess 2

xiv. For a review see Hughes DL. Org. Prep. Proceed. Int 1996;28:127-164.

$\mathrm{xv}$. In situ ${ }^{1} \mathrm{H}$ NMR monitoring of the homogeneous reaction mixture showed complete consumption of $\mathbf{4 7}$ and 2 with concomitant clean and exclusive formation of $\mathbf{4 9}$

xvi. The oxidation of the more electron rich pyrroloindolozine substructure is greatly accelerated in the presence of acid. 


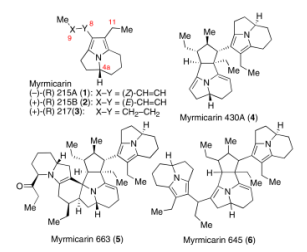

FIGURE 1.

Members of the myrmicarin alkaloids. 


\section{A. Azafulvenium Ion Chemistry:}
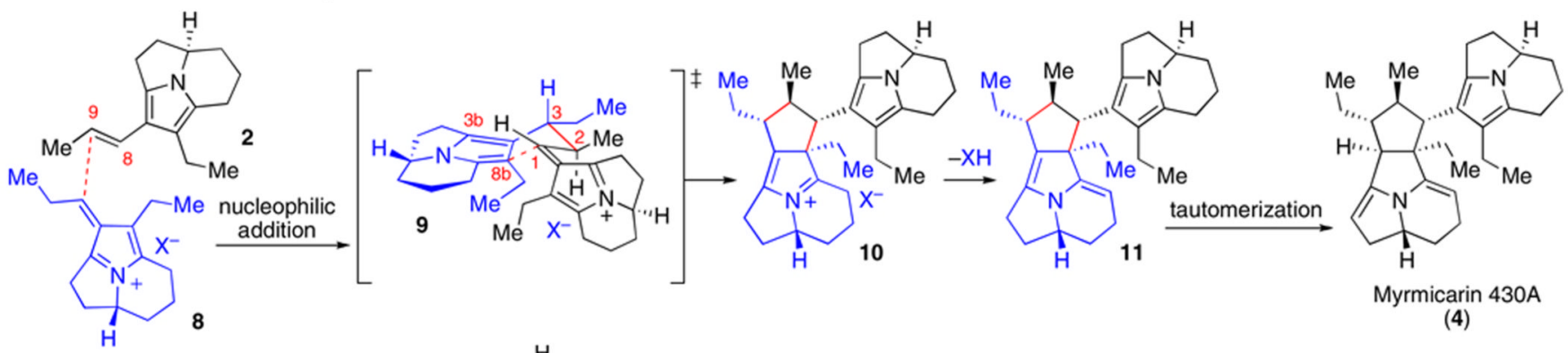

(4)

B. Cycloaddition Chemistry:

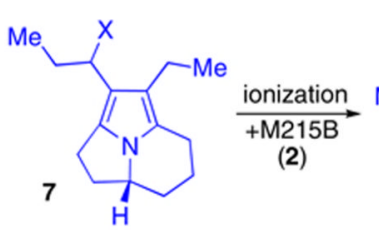

C. Free-radical Chemsitry:
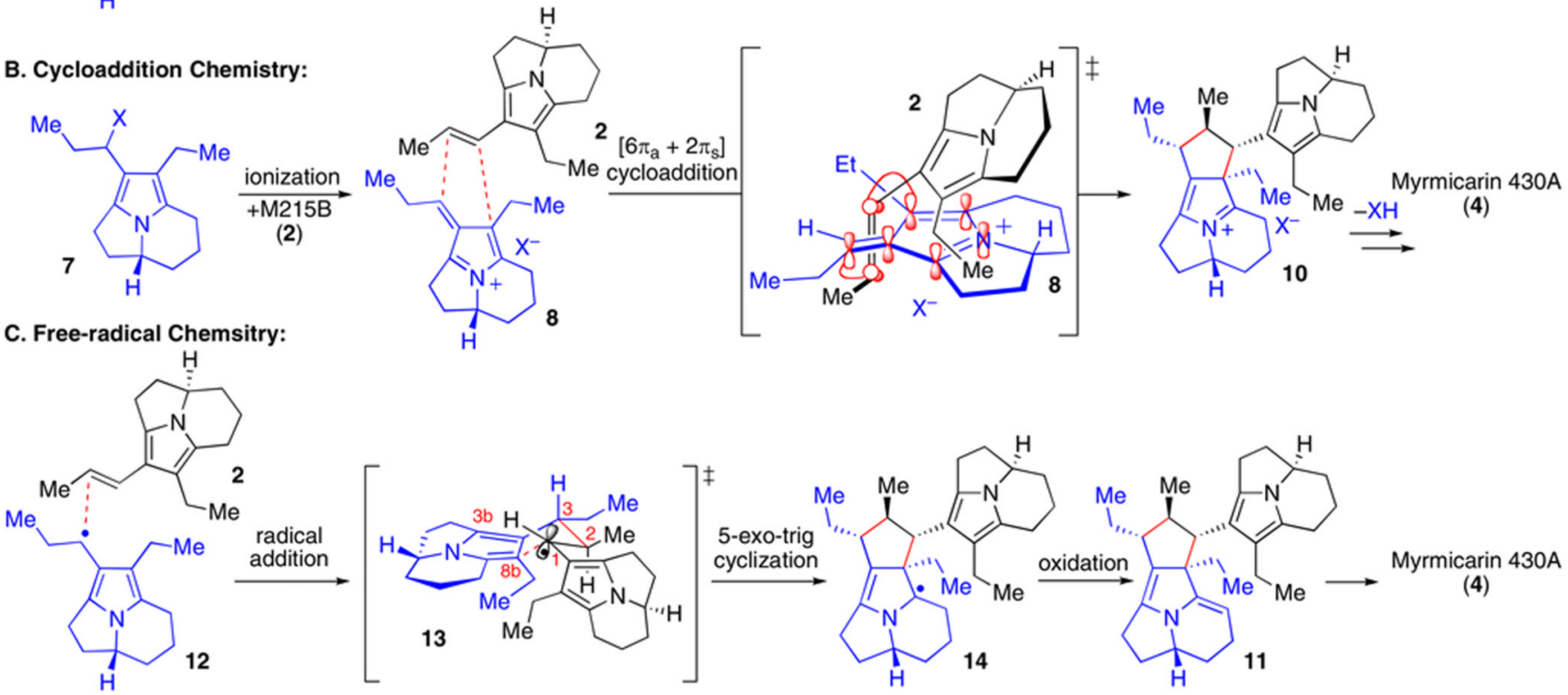

SCHEME 1.

Our proposed biomimetic dimerization of pyrroloindolizines for the synthesis of myrmicarin 430A (4). 


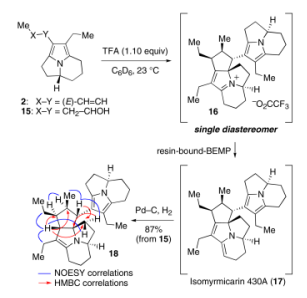

SCHEME 2.

Our synthesis of isomyrmicarin 430A (17) by direct dimerization of (+)-myrmicarin 215B (2). ${ }^{\text {iia }}$ 


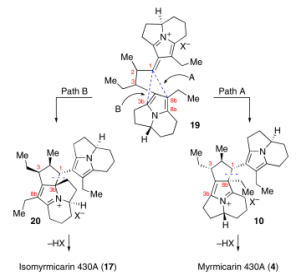

SCHEME 3.

Bond formation leading to myrmicarin 430A (4, Path A) and isomyrmicarin 430A (17, Path B). 


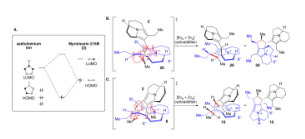

SCHEME 4.

A) FMO analysis of a concerted $\left[6 \pi_{\mathrm{a}}+2 \pi_{\mathrm{s}}\right]$ cycloaddition between an azafulvenium ion and an alkene. B) Possible cycloaddition involving the $E$-azafulvenium ion 25 and (+)-

myrmicarin 215B (2) leading to iminium ion 20 en route to isomyrmicarin $430 \mathrm{~A}$ (17). C) Potential cycloaddition leading to iminium ion 10 en route to myrmicarin $430 \mathrm{~A}(\mathbf{4})$. 


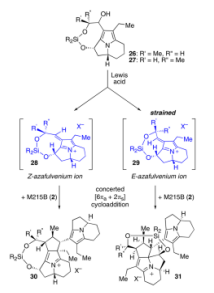

SCHEME 5.

Expected heptacycles from a $\left[6 \pi_{\mathrm{a}}+2 \pi_{\mathrm{s}}\right]$ cycloaddition between $\mathbf{2}$ and azafulvenium ions $\mathbf{2 8}$ and 29. 

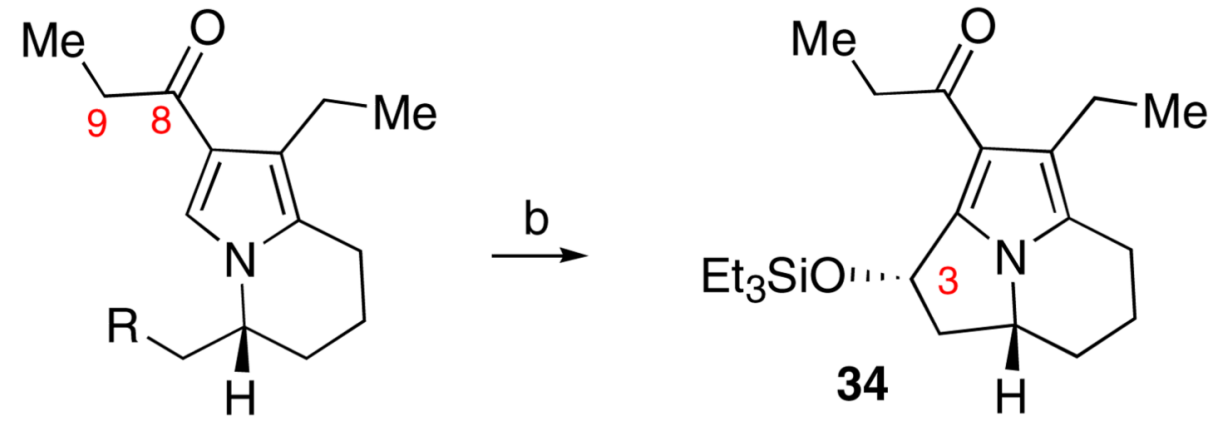

32: $\mathrm{R}=\mathrm{CH}_{2} \mathrm{OH}$
33: $\mathrm{R}=\mathrm{CHO}$
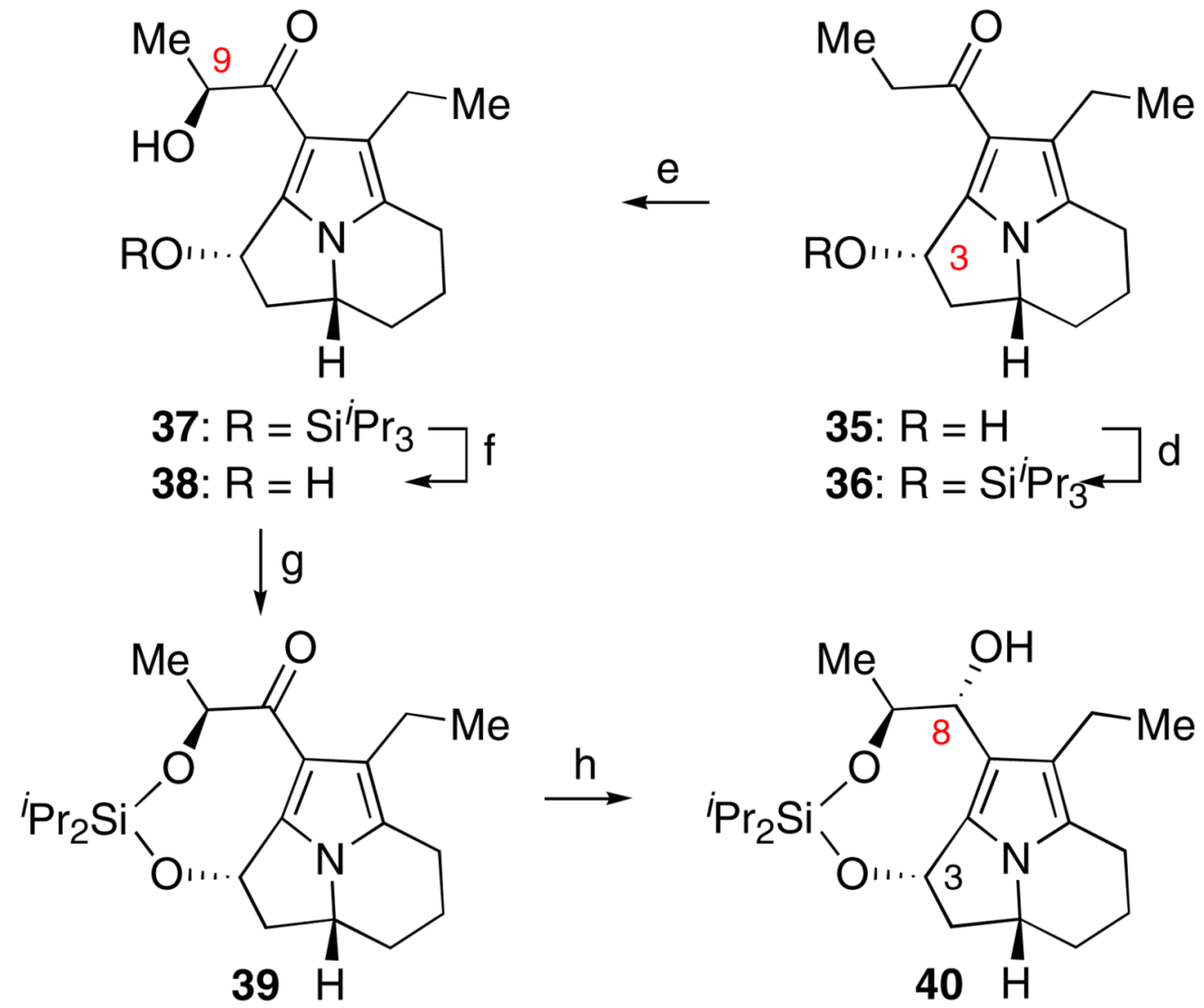

SCHEME 6.

Synthesis of azafulvenium ion precursor 40. Conditions: a) IBX, DMSO, 82\%. b) TESOTf, 2,6-lutidine, $\mathrm{PhH}, 23{ }^{\circ} \mathrm{C}, 4: 1 \mathrm{dr}$. c) TBAF, THF, 81\% (2-steps). d) TIPSOTf, 2,6-lutidine, $\mathrm{CH}_{2} \mathrm{Cl}_{2},-40 \rightarrow 0{ }^{\circ} \mathrm{C} .82 \%$. e) KHMDS, Davis oxaziridine, THF $-78{ }^{\circ} \mathrm{C}, 90 \%, 5: 1 \mathrm{dr}$. f) TBAF, THF, 92\%. g) ${ }^{i} \mathrm{Pr}_{2} \mathrm{SiCl}_{2}$, DMAP, DMF, 77\%. h) LAH, Et $2 \mathrm{O},-78 \rightarrow 0{ }^{\circ} \mathrm{C}, 77 \%, 6: 1$ dr. 


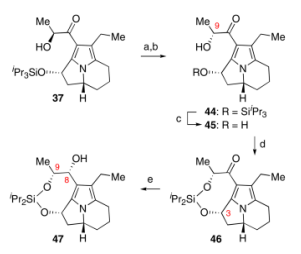

SCHEME 7.

Synthesis of (9R)-alcohol 47. Conditions: a) $\mathrm{PPh}_{3}$, DEAD, $p-\mathrm{NO}_{2} \mathrm{C}_{6} \mathrm{H}_{4} \mathrm{CO}_{2} \mathrm{H}, \mathrm{THF}, 61 \%$ (72\% brsm). b) $\mathrm{LiOH}, \mathrm{THF}-\mathrm{H}_{2} \mathrm{O}, 50{ }^{\circ} \mathrm{C}, 100 \%$. c) TBAF, THF, 92\%. d) ${ }^{i} \mathrm{Pr}_{2} \mathrm{SiCl}_{2}, \mathrm{DMAP}$, DMF, $29 \%$. e) $\mathrm{LAH}, \mathrm{Et}_{2} \mathrm{O},-78 \rightarrow 0^{\circ} \mathrm{C}, 16 \%$ (24\% brsm). 


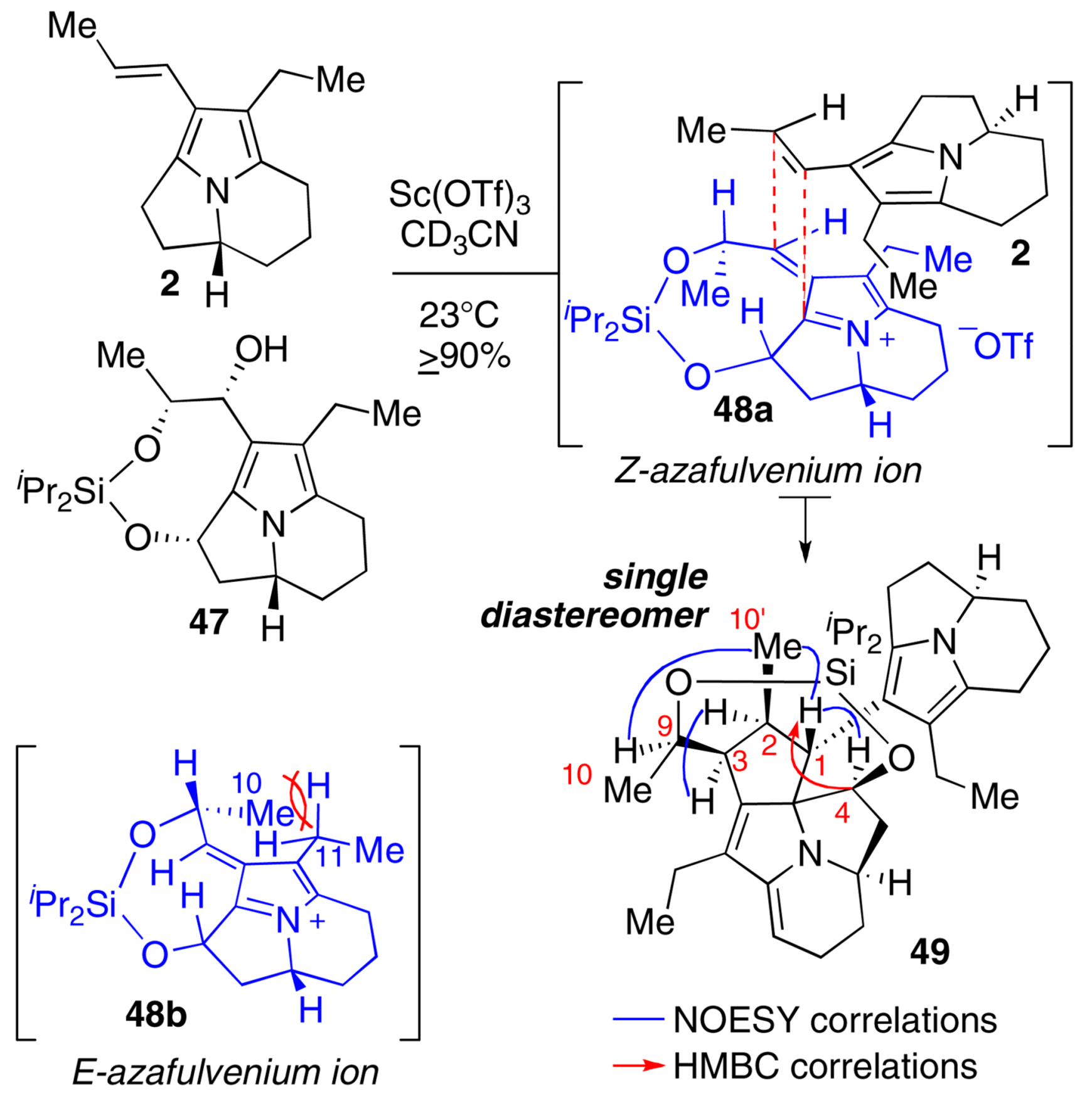

SCHEME 8.

Diastereoselective condensation of (+)-myrmicarin 215B (2) and alcohol 47. 

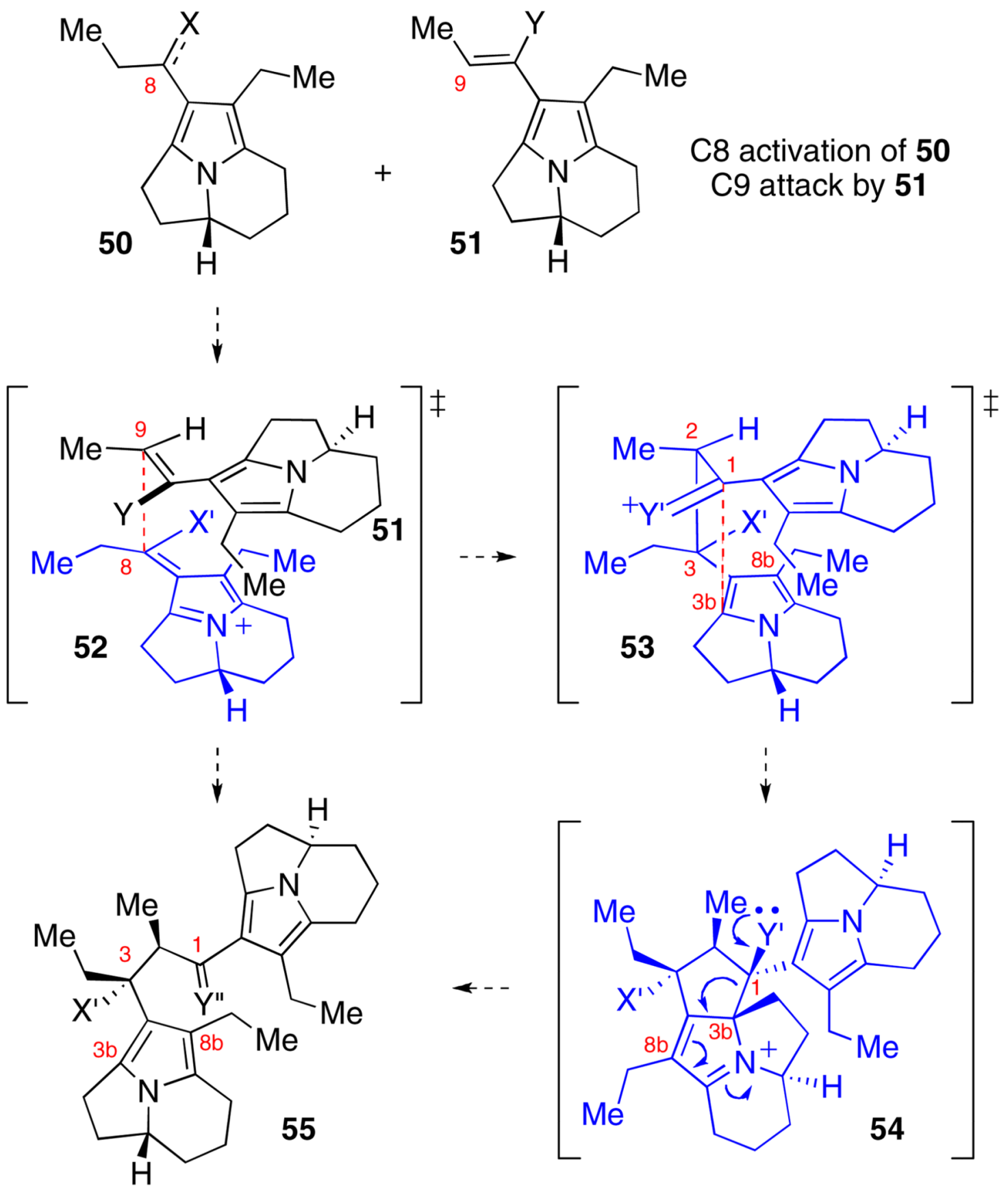

SCHEME 9.

Directed heterodimerization of functional pyrroloindolizines. 


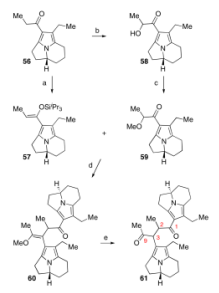

\section{SCHEME 10.}

Synthesis of the hexacycle $\mathbf{6 1}$ by directed dimerization of functional pyrroloindolizines. Conditions: a) TIPSOTf, $\mathrm{Et}_{3} \mathrm{~N}, \mathrm{CH}_{2} \mathrm{Cl}_{2},-40{ }^{\circ} \mathrm{C}, 100 \%$. b) KHMDS; Davis'-oxaziridine, THF, $-78{ }^{\circ} \mathrm{C}, 86 \%, 5: 2$ dr. c) NaH, MeI, DMF, $23{ }^{\circ} \mathrm{C}, 94 \%$. d) $\mathrm{Tf}_{2} \mathrm{O}, 2,6$-di- ${ }^{t}$ butyl-4methylpyridine, $\mathrm{CH}_{2} \mathrm{Cl}_{2},-78{ }^{\circ} \mathrm{C}, 84 \%$. e) PPTS, $\mathrm{H}_{2} \mathrm{O}, \mathrm{MeCN}, \mathrm{C}_{6} \mathrm{H}_{6}, 23{ }^{\circ} \mathrm{C}, 70 \%$. 


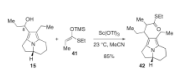

EQUATION 1.

Activation of $\mathbf{1 5}$ and $\pi$-nucleophilic trapping. 

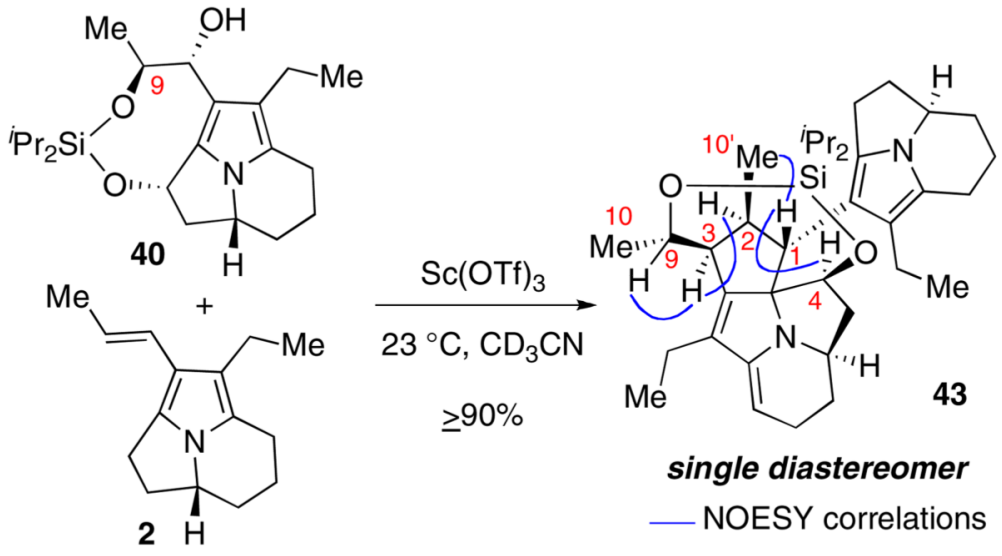

EQUATION 2.

Diastereoselective condensation of (+)-myrmicarin 215B (2) and alcohol 40. 


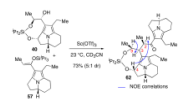

EQUATION 3.

Diastereoselective synthesis of hexacycle $\mathbf{6 2}$ from silyl enol ether $\mathbf{5 7}$ and the conformationally restricted pyrroloindolizine $\mathbf{4 0}$. 
